This is an Accepted Manuscript of an article published by Taylor \& Francis in Applied Economics on 23 March 2017, available online: http:// www.tandfonline.com/10.1080/00036846.2017.1305092

\title{
MODELS OF MORTALITY RATES - ANALYSING THE RESIDUALS
}

\section{COLIN O’HARE ${ }^{\dagger}$, YOUWEI LI ${ }^{\ddagger}$}

ABSTRACT. The area of mortality modelling has received significant attention over the last 20 years owing to the need to quantify and forecast improving mortality rates. This need is driven primarily by the concern of governments, professionals, insurance and actuarial professionals and individuals to be able to fund their old age..In particular, to quantify the costs of increasing longevity we need suitable model of mortality rates that capture the dynamics of the data and forecast them with sufficient accuracy to make them useful. In this paper we test several of those models by considering the fitting quality and in particular, testing the residuals of those models for normality properties. In a wide ranging study considering 30 countries we find that almost exclusively the residuals do not demonstrate normality. Further, in hurst tests of the residuals we find evidence that structure remains that is not captured by the models.

JEL Classification: C51, C52, C53, G22, G23, J11

Keywords and Phrases: Mortality, stochastic models, forecasting, structural breaks. hurst exponents

Date: Latest version: October 28, 2014.

${ }^{\dagger}$ Department of Econometrics and Business Statistics, Monash University Melbourne, Vic 3800, Australia, ${ }^{\ddagger}$ School of Management, Queen's University of Belfast, BT9 5EE, Belfast, United Kingdom. Tel.: +44 289097 4671; Fax: +44 289097 4201. Emails: colin.ohare@monash.edu and y.li@qub.ac.uk.

Acknowledgements: A version of this paper was presented at the IME Congress in Shanghai in 2014, the authors are grateful for the comments received. 


\section{INTRODUCTION}

The rapid growth in the development of models of mortality designed to capture patterns in mortality data and accurate forecast and quantify future mortality rates has been dramatic. Over the past recent decades, life expectancy in developed countries has risen to historically unprecedented levels and there is clearly a need from a demographic, financial, social and actuarial perspective to understand and predict these improvements for the future. The prospects of future reductions in mortality rates are of fundamental importance in various areas such as public health and old age care planning, social insurance planning, welfare benefit forecasting and economic policy. Over recent years, significant progress has been made in mortality forecasting (for a recent review see Booth and Tickle, 2008) with the most popular approaches to long-term forecasting being based on the Lee and Carter (1992) model. IA time series model, it describes the movement of age-specific mortality as a function of a latent level of mortality, also known as the overall mortality index, which can be forecasted using simple time-series methods. The method was initially used to forecast mortality in the US, but since then has been applied to many other countries (amongst others see Tuljapurkar and Boe, 1998; Carter and Prskawetz, 2001; Lee and Miller, 2001; Booth et al., 2002; Brouhns et al., 2002; Renshaw and Haberman, 2003 and Koissi et al., 2005).

The success of the Lee Carter model can be seen in the number and variety of mortality models that extend the Lee Carter approach (see O'Hare and Li 2012) for examples of these extensions. One thread of extensions to the Lee Carter model involves including additional latent age and period effects with the objective of better fitting the data, producing a less simplistic correlation structures between ages and capturing the non linear profile of mortality data. This has led for example to the models of Renshaw and Haberman (2003), Cairns, Blake and Dowd (2006,2008, 2009), Plat (2009) and O'Hare and Li (2013) for example.. These models extend the Lee Carter approach by including additional period effects and in some cases cohort effects and improve upon each other by producing better fits to the data and in the main better forecasts. In the literature however, there has been limited attempts to test the fitting of such models. The majority of papers calculate point estimates of the average errors produced between the fitted 
and actual rates using one of several measures (for example root mean square errors, mean average percentage errors etc). There has been very little work looking at the patterns of such errors.

One such paper that considered the shape of the residuals in a range of mortality models is that of Dowd et al 2010 where the authors assess the residuals for normality carrying out several tests of the mean, variance and skewness of the residuals. Dowd et al 2010 fitted a range of models, primarily the Lee Carter (1992) model and a selection of CBD models to data and then after calculating the in sample forecasts they derived standardised residuals from the forecasts and tested these for normality. Their paper concluded that none of the models considered performed well under these tests. In this paper we extend and modify this work in three ways. Firstly, rather than forecasting and tests the derived residuals we calculate the residuals directly from the fitted models. This will enable us to test the model to ensure that all of the structure of the mortality data is being captured prior to forecasting. Secondly, we extend the work by considering several multi factorial models (namely Plat (2009) and O'Hare and Li (2013)) that were not present in eh prior study. Finally, in addition to the normality tests we calculate hurst exponents for each of the residual time series for each country and gender and comment of the findings therein.

The paper is organized as follows. Section 2 presents a brief review of extrapolative models such as the Lee-Carter model and its extensions. Section 3 discusses the methodology we use to test the residuals for normality. In section 4 we discuss the data we have used in this study and in section 5 we presents the results of our analysis. Finally, section 6 concludes with some ideas for further research.

\section{LEE-CARTER AND ITS VARIANTS}

The current leading method for forecasting mortality rates is the stochastic extrapolation approach. In this method data is first transformed (by taking natural logarithms) and then analysed using statistical methods to identify and extract patterns. These patterns are then forecast using well known time series approaches. The resulting forecasts are then used to predict future mortality rates. The first and most well known stochastic mortality model of this type is the Lee and Carter (1992) model. Based on US data the model uses a stochastic, time series framework to identify a single period effect pattern in the natural logarithm of mortality rates. This linear 
trend over time is extracted and using Box-Jenkins an appropriate ARIMA processes is fitted to the data (a random walk with drift in each case). The random walk with drift is forecast and resulting future mortality rates predicted. Also known as a one factor or one principle component approach the model became a benchmark and underlined a new approach to modelling mortality rates for several reasons: the model has an extremely simple structure and so is very easy to communicate; and the use of the random walk with drift enabled the authors not only to predict the expected future mortality rates but also to visualise the uncertainty associated with the predictions. The Lee-Carter model, outlined below includes two age dependent parameters $a_{x}$ and $b_{x}$ which respectively represent the intercept and gradient for the log mortality rate at each age and the time or period trend $\kappa_{t}$ which is forecast using a random walk with drift:

$$
\ln \left(m_{x, t}\right)=a_{x}+b_{x} \kappa_{t}+\epsilon_{x, t}
$$

where $a_{x}$ and $b_{x}$ are age effects and $\kappa_{t}$ is a random period effect.

The model is known to be over parameterised and applying the necessary constraints as in the original Lee and Carter (1992) paper the $a_{x}$ are given by

$$
a_{x}=\frac{1}{N} \sum_{t=1}^{N} \ln m_{x, t} .
$$

In the original paper the bilinear part $b_{x} \kappa_{t}$ of the model specification was determined as the first singular component of a singular value decomposition (SVD), with the remaining information from the SVD considered to be part of the error structure. The $\kappa_{t}$ were then estimated and refitted to ensure the model mapped onto historic data. Finally the subsequent time series $\kappa_{t}$ was used to forecast mortality rates.

Despite the attractiveness of the models simplicity it has several weaknesses. Among many discussions of the Lee-Carter model, Cairns et al. (2006, 2009, and 2011) summarized the main disadvantage of the model as having only one factor, resulting in mortality improvements at all ages being perfectly correlated (trivial correlation structure). They also note that for countries where a cohort effect is observed in the past, the model gives a poor fit to historical data. The uncertainty in future death rates is proportional to the average improvement rate $b_{x}$ which for high ages can lead to this uncertainty being too low, since historical improvement 
rates have often been lower at high ages. Also, the model can result in a lack of smoothness in the estimated age effect $b_{x}$.

Despite the weaknesses of the Lee-Carter model it's simplicity has led to it being taken as a benchmark against which other stochastic mortality models can be assessed. There has been a significant amount of literature developing additions to, or modifications of, the Lee-Carter model. For example Booth et al. (2002), Brouhns et al. (2002), Lee and Miller (2001), Girosi and King (2005), De Jong and Tickle (2006), Delwarde et al. (2007) and Renshaw and Haber$\operatorname{man}(2003,2006)$.

Renshaw and Haberman (2006) modified the Lee-Carter model by simply adding a factor to capture cohort effect. The model does have a much better fit for countries such as the UK where a cohort effect has been identified, however it suffers from a lack of robustness perhaps due to the presence of more than one local maximum in the likelihood function. Among others, for instance Currie (2006) noted that if the model was fitted using data from 1961-2000 then the parameters showed qualitatively different characteristics to those obtained when fitting to data from 1981-2000. Furthermore, as noted by Currie (2006), although the model incorporates the cohort effect, for most of the simulated mortality rates the correlation structure is still trivial with the simulated cohort parameters only being relevant for the higher ages at the far end of the projection. Following this analysis Currie (2006) applied a simplified age-period-cohort model of Clayton and Schifflers (1987) to mortality which removed the robustness problem but at the expense of the fitting quality.

Cairns, Blake and Dowd (2006) observed that for England \& Wales and United States data, the fitted cohort effect appeared to have a trend in the year of birth. This suggested that the cohort effect was compensating for the lack of a second age-period effect, as well as trying to capture the cohort effect in the data. This led them to introduce a two factor model (CBD model hereafter),

$$
\operatorname{logit}\left(q_{x, t}\right)=\kappa_{t}^{1}+\kappa_{t}^{2}(x-\bar{x})+\epsilon_{x, t}
$$

where $\bar{x}$ is the mean age in the sample range and $\left(\kappa_{t}^{1}, \kappa_{t}^{2}\right)$ are assumed to be a bivariate random walk with drift. The model fits a logistically transformed initial rate of mortality, $q_{x, t}$, using two factors which are both period factors. There is no cohort effect allowed for however, this was rectified in Cairns et al. (2009), namely capturing the cohort effect as an additional effect on top 
of the two age-period effects. The initial rate of mortality can be related to the central rate of mortality $m_{x, t}$ through: $q_{x, t}=1-\exp \left(-m_{x, t}\right)$. All these models have multiple factors resulting in a non-trivial correlation structure which mirrors the reality that improvements in mortality rates are different for different age ranges. A further adaptation was also created allowing for the cohort effect to diminish over time. The main problem with these models arises from the fact that they were designed for higher ages and so ignored the modelling of mortality at the lower ages (for example the accident hump). Cairns et al. (2009) argue that the significant cost associated with mortality is at the older ages and thus their modelling focused on those ages. When using these models for full age ranges, the fit quality is relatively poor and the projections are biologically unreasonable.

Plat (2009) wanted to develop a model which maintained the good aspects of the existing models whilst leaving out the weaker features. The result was a four factor model which took its beginnings from the Lee-Carter model and which added factors to capture the second ageperiod effect, as per the CBD model and the cohort effect, as per the Renshaw and Haberman (2006) model. The innovation in the Plat model was to then add a further period factor affecting only the lower ages and designed to allow the model to fit to the whole age range. The Plat model specification is given by:

$$
\ln \left(m_{x, t}\right)=a_{x}+\kappa_{t}^{1}+\kappa_{t}^{2}(\bar{x}-x)+\kappa_{t}^{3}(\bar{x}-x)^{+}+\gamma_{t-x}+\epsilon_{x, t},
$$

where the $a_{x}$ is similar to that of the Lee-Carter model and makes sure that the overall shape of the mortality curve by age is reasonable, the $\kappa_{t}^{1}$ and $\kappa_{t}^{2}$ model the mortality rates as in the CBD model and the $\kappa_{t}^{3}$ models the effects specific to the lower ages only where $(\bar{x}-x)^{+}$takes the value $(\bar{x}-x)$ when this is positive and zero otherwise. Finally the $\gamma_{t-x}$ models the cohort effect.

O'Hare and Li (2012) modified the Plat (2009) model to provide a better fit for a wider age range including ages 5-20. They improved the Plat specification by including a quadratic lower age effect. Their model specification is given below (OL model hereafter):

$$
\ln \left(m_{x, t}\right)=a_{x}+\kappa_{t}^{1}+\kappa_{t}^{2}(\bar{x}-x)+\kappa_{t}^{3}\left((\bar{x}-x)^{+}+\left[(\bar{x}-x)^{+}\right]^{2}\right)+\gamma_{t-x}+\epsilon_{x, t},
$$


where $a_{x}$ makes sure that the basic shape of the mortality curve over ages is in line with historical observations as in the Lee-Carter model (1) and the $\kappa_{t}^{1}$ factor represents changes in the level of mortality for all ages. Following the reasoning in Cairns et al. (2006), the (long-term) stochastic process for this factor should not be mean reverting. The $\kappa_{t}^{2}$ factor allows changes in mortality to vary between ages reflecting the historical observation that improvement rates can differ for different age classes and $\kappa_{t}^{3}$ models the effects specific to the lower age only as in the Plat model (3). The adjusted coefficient of $\kappa_{t}^{3}$ is designed to capture some of the non-linear effects observed at the lower ages, the "quadratic lower age effect".

\section{DATA}

The data that we use in this paper comes from the Human Mortality Database. ${ }^{1}$ The data available for each country includes number of deaths $D_{x, t}$ and exposure to death $E_{x, t}$ for lives aged $x$ last birthday during year $t$. We can use this to gain a proxy for the central mortality rate for lives aged $x$ during year $t$ as:

$$
m_{x, t}=\frac{D_{x, t}}{E_{x, t}}
$$

The data provides an estimate of the true mortality due to issues with the recording of data. Death data tends to be recorded accurately, with death certificates in most cases. However, exposure data is taken from census data which may only be accurately recorded every 5 or 10 years adjusting these figures for migration, deaths and births etc. The resulting mortality estimates are therefore quite noisy, particularly at the older ages where there is less data available. Data is available going back to the mid nineteenth century in some cases but we have restricted this study to data from 1960-2009 in order to have a consistent period across all countries and we have considered the following 30 countries in table 1 in this study.

The wide range of countries give a good spread of populations both geographically and in terms of economic development. The inclusion of Male and Female data also enables gender differences to be considered. We focus on the age range 20-89 for several reasons. Firstly, the models upon which we have based our comparisons are also fitted to this age range. Secondly, and as identified by Currie (2011), data at the older ages provide additional problems in terms

\footnotetext{
${ }^{1}$ This can be found at http://www.mortality.org/. The database is maintained in the Department of Demography at the University of California, Berkeley, USA, and at the Max Planck Institute for Demographic Research in Rostock, Germany.
} 
TABLE 1. Countries considered in this study along with HMD codes

\begin{tabular}{lr|rr}
\hline HMD Code & Country & HMD Code & Country \\
\hline nor & Norway & pol & Poland \\
fin & Finland & usa & United States of America \\
lit & Lithuania & por & Portugal \\
spa & Spain & ukr & Ukraine \\
ast & Austria & czr & Czechoslovakia \\
fra & France & ity & Italy \\
swe & Sweeden & rus & Russia \\
blr & Belarus & den & Denmark \\
nth & Netherlands & jap & Japan \\
swi & Switzerland & svk & Slovakia \\
bel & Belgium & est & Estonia \\
hun & Hungary & lat & Latvia \\
nzd & New Zealand & ukt & United Kingdom \\
bul & Bulgaria & uks & Scotland \\
can & Canada & uke & England \\
\hline
\end{tabular}

of the reliability. Indeed in several cases mortality rates determined using older data appear to fall sharply beyond age 95 .

\section{Methodology}

We begin by fitting each of the models considered to the data above for the 30 countries considered and for both males and females. In this paper we will consider the 4 models Lee Carter (1992), CBD(2006), Plat (2009) and O'Hare and Li(2013). We fit the models using a maximum likelihood approach using code developed in $\mathrm{R}$ and publicly available for several of the models. The results of fitting are assessed and presented using three point measures of fit quality outlined below.

The average error, $E 1$ - this equals the average of the standardized errors,

$$
E 1=\frac{1}{X_{1}-X_{2}+1} \sum_{x=X_{1}}^{X_{2}} \sum_{t=1}^{T} \frac{\left(\hat{m}_{x, t}-m_{x, t}\right)}{\hat{m}_{x, t}},
$$

this is a measure of the overall bias in the projections. The average absolute error, $E 2$ - this equals the average of absolute value of the standardized errors,

$$
E 2=\frac{1}{X_{1}-X_{2}+1} \sum_{x=X_{1}}^{X_{2}} \sum_{t=1}^{T}\left|\frac{\hat{m}_{x, t}-m_{x, t}}{\hat{m}_{x, t}}\right|
$$

this is a measure of the magnitude of the differences between the actual and projected rates. The standard deviation of the error, $E 3$ - this equals the square root of the average of the squared 
errors,

$$
E 3=\sqrt{\frac{1}{X_{1}-X_{2}+1} \sum_{x=X_{1}}^{X_{2}} \sum_{t=1}^{T}\left(\frac{\hat{m}_{x, t}-m_{x, t}}{\hat{m}_{x, t}}\right)^{2}} .
$$

where $X_{1}$ and $X_{2}$ and the age limits of our sample $X_{1}=20$ and $X_{2}=89$, and $T=60$ is the number of years of data we have in our sample.

The models are fitted by assuming that death rates are drawn from a poisson distribution with parameter given by $E_{x, t} m_{x, t}$. We then calculate the corresponding fitted mortality rates $\hat{m}_{x, t}$ and calculate the standardised residuals using the following formula

$$
\frac{\hat{m}_{x, t}-m_{x, t}}{\sqrt{m_{x, t} / E_{x, t}}}
$$

This approach to calculating the residuals is consistent with that of the Dowd et al 2010 paper and should represent samples drawn from a standard normal distribution if indeed the residuals are reflecting no more than random noise.The tests used in this section aim to identify whether the mortality residuals described above are consistent with iid $\mathrm{N}(0,1)$. We carry out the following tests on the matrix of mortality residuals:

- A t-test of the prediction that their mean should be 0 .

- A variance ratio (VR) test of the prediction that the variance should be 1 (see Cochrane, 1988; Lo and MacKinley, 1988, 1989), and

- A JarqueBera normality test based on the skewness and kurtosis predictions (see Jarque and Bera, 1980).

In addition, we calculate hurst exponent, $\mathrm{H}$, for each of the time series extracted from the residuals. The Hurst exponent is referred to as the "index of dependence" or "index of longrange dependence". It quantifies the relative tendency of a time series either to regress strongly to the mean or to cluster in a direction. A value $\mathrm{H}$ in the range $0.5<H<1$ indicates a time series with long-term positive autocorrelation, meaning both that a high value in the series will probably be followed by another high value and that the values a long time into the future will also tend to be high. A value in the range $0<H<0.5$ indicates a time series with long-term switching between high and low values in adjacent pairs, meaning that a single high value will probably be followed by a low value and that the value after that will tend to be high, with this tendency to switch between high and low values lasting a long time into the future. A value of 
$H=0.5$ can indicate a completely uncorrelated series, but in fact it is the value applicable to series for which the autocorrelations at small time lags can be positive or negative but where the absolute values of the autocorrelations decay exponentially quickly to zero. Given that we are expecting the residuals to be samples for a $\mathrm{N}(0,1)$ distribution we should not expect any corelations between residuals. In other words a husrt exponent of 0,5 would be ideal.

The Hurst exponent, $\mathrm{H}$, is defined in terms of the asymptotic behaviour of the rescaled range as a function of the time span of a time series as follows

$$
E\left[\frac{R(n)}{S(n)}\right]=C n^{H} \_ \text {as } \_n \rightarrow \infty
$$

where;

- $R(n)$ is the range of the first $n$ values, and $S(n)$ is their standard deviation

- $E[]]$ is the expected value

- $n$ is the time span of the observation (number of data points in a time series)

- $C$ is a constant

In order to consider the hurst exponent analysis we must apply it to a time series of residuals not a matrix of residuals. We therefore consider both the age dimension and the period dimension separately. In both cases we should not expect any correlations between residuals across age nor should we expect any across the period dimension. In the empirical section following we present the analysis in both dimensions and comment accordingly.

\section{[I AM UP TO HERE]}

\section{EMPIRICAL ANALYSIS}

In this action we present and discuss our findings. We firstly show the fitting results measured using the standard E1, E2 and E3 measures of fitting quality. These are calculated as shown in the methodology section and in the main confirm the reported findings of each of the previous papers proposing the models. We follow this with a discussion of some of the residuals calculated for each of the countries in the study. We present some of the residual plots and comment on some common characteristics we find. Finally, we empirically test the residuals using a range of tests as discussed above. 
5.1. Fitting the models and assessing with point estimates. We consider each of the 30 countries covered in the paper for both male and female data, fitting the models to data from 1960 - 2009. We present the results in tables including all countries but where we only populate the cases where a structural break was present. We present results below in tables 4 - ?? using the three measures of error E1, E2 and E3 outlines earlier. 


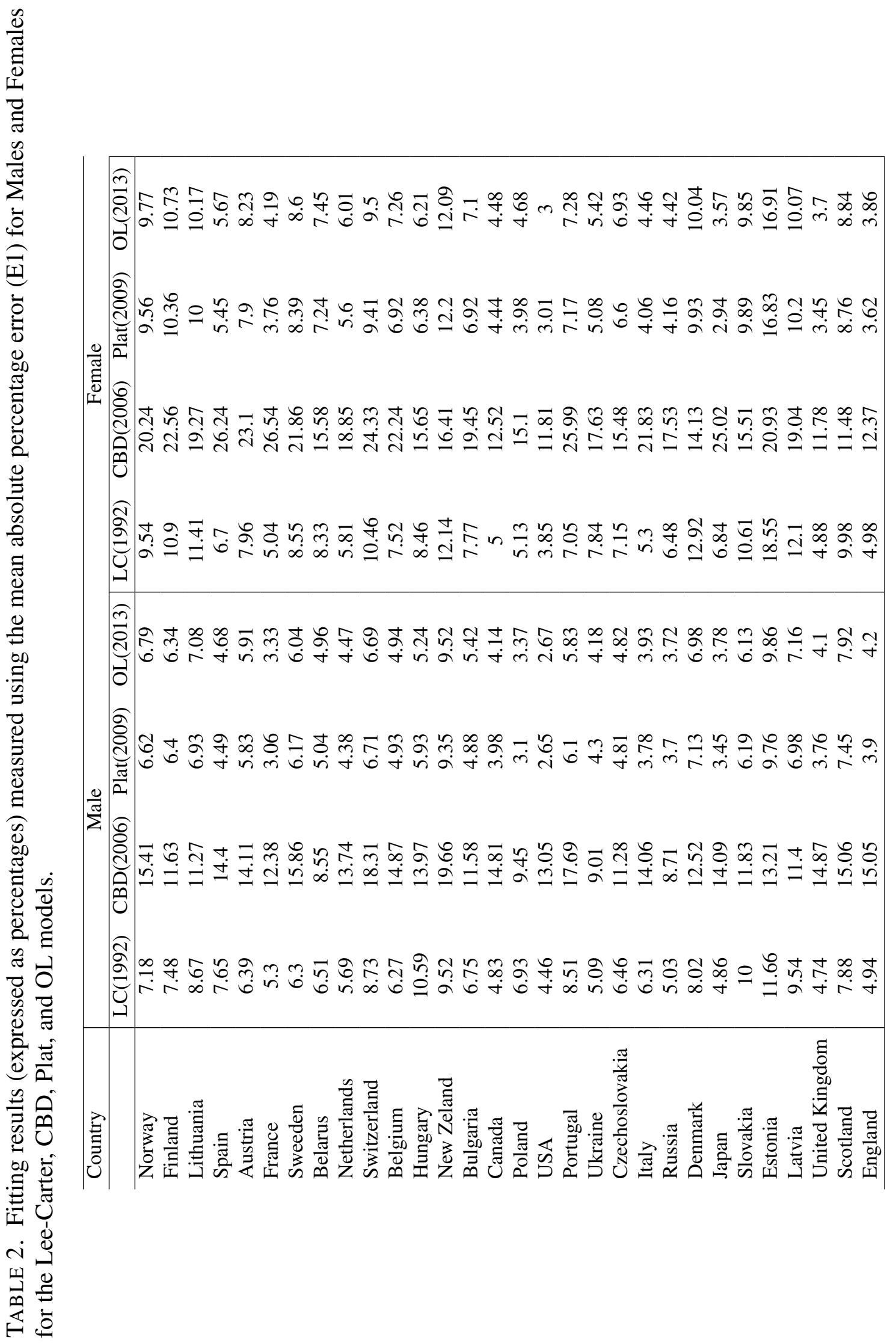




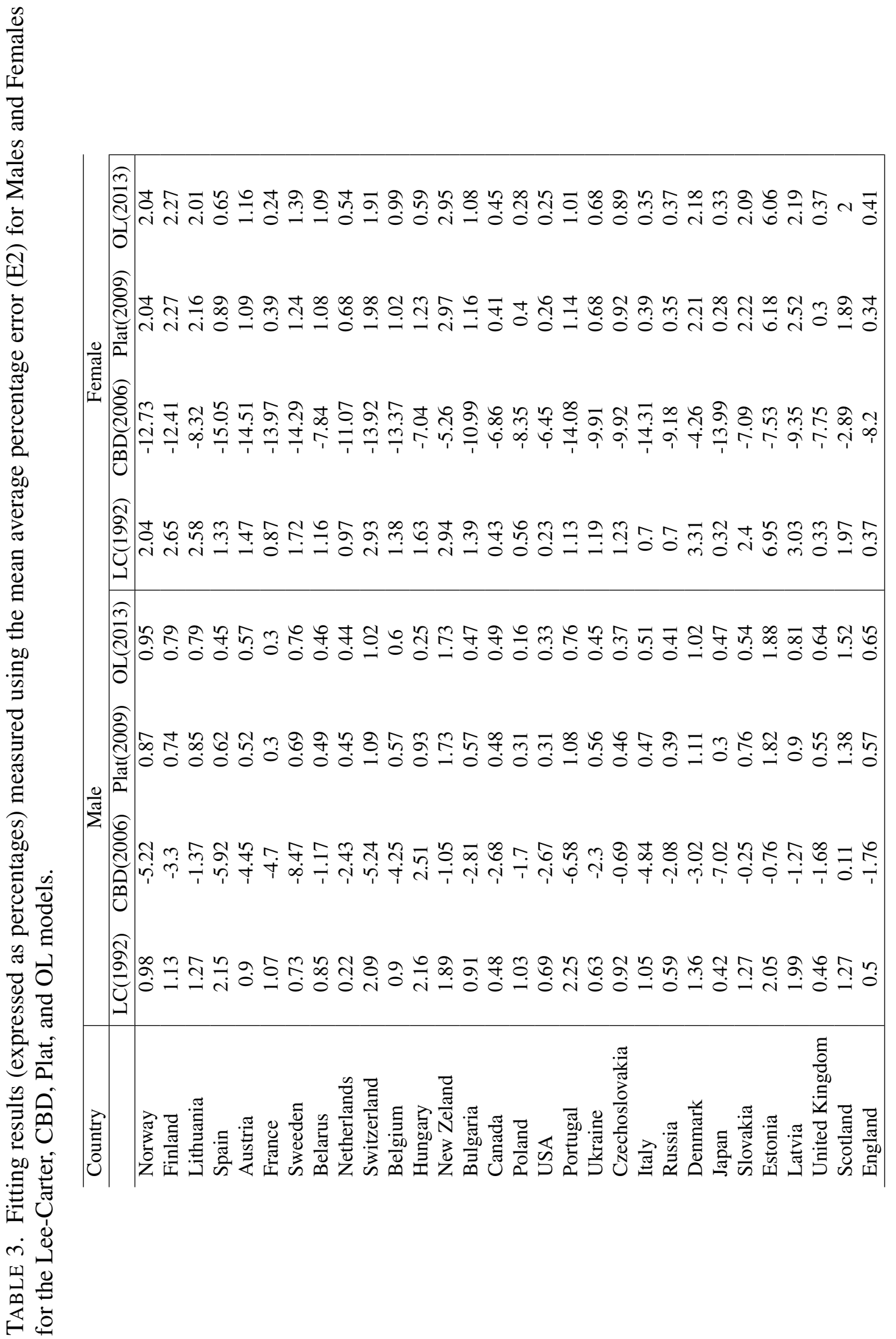




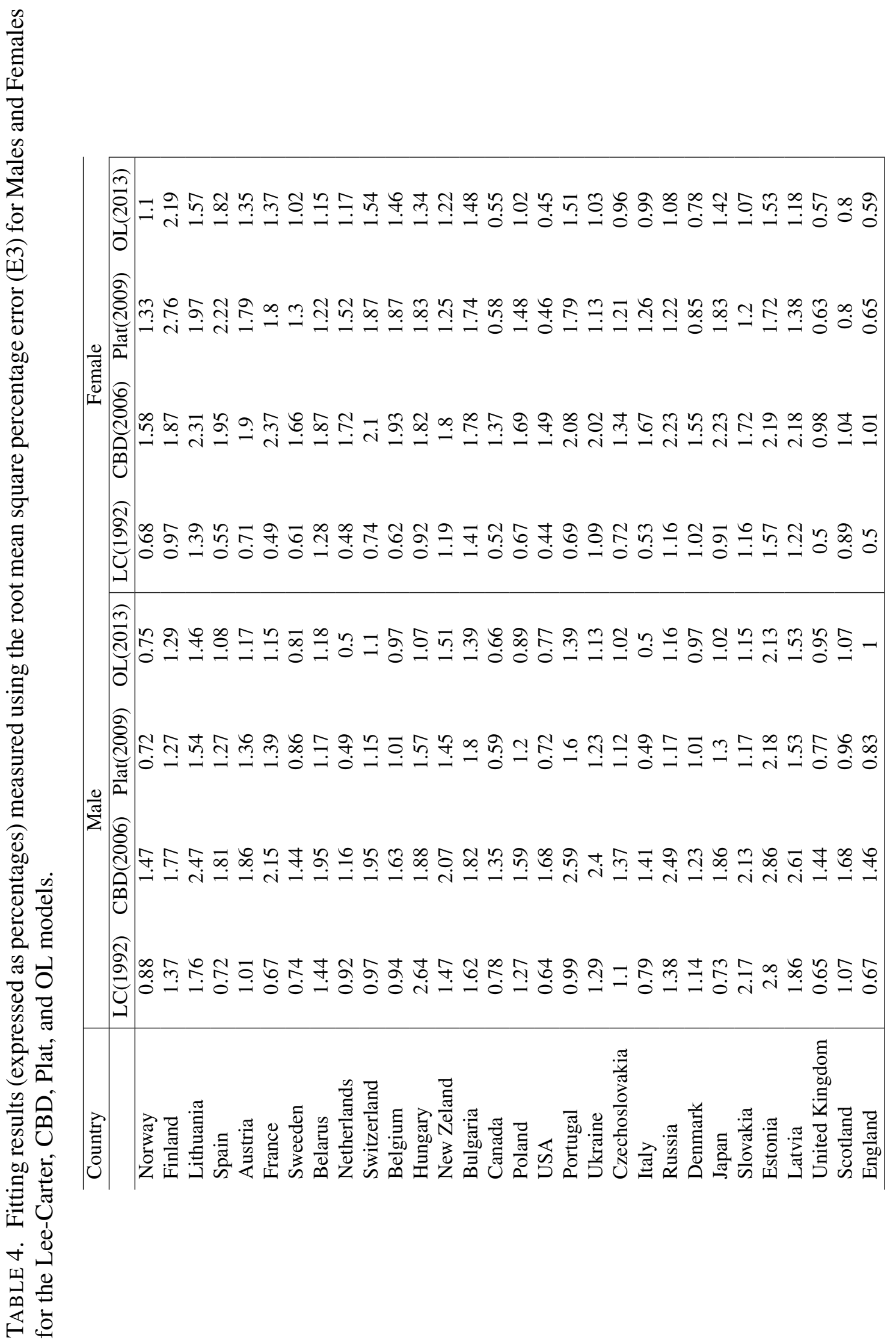


5.2. Analysing the residuals.

5.3. Statistical tests of the residuals.

5.3.1. $t$-tests of the mean. 


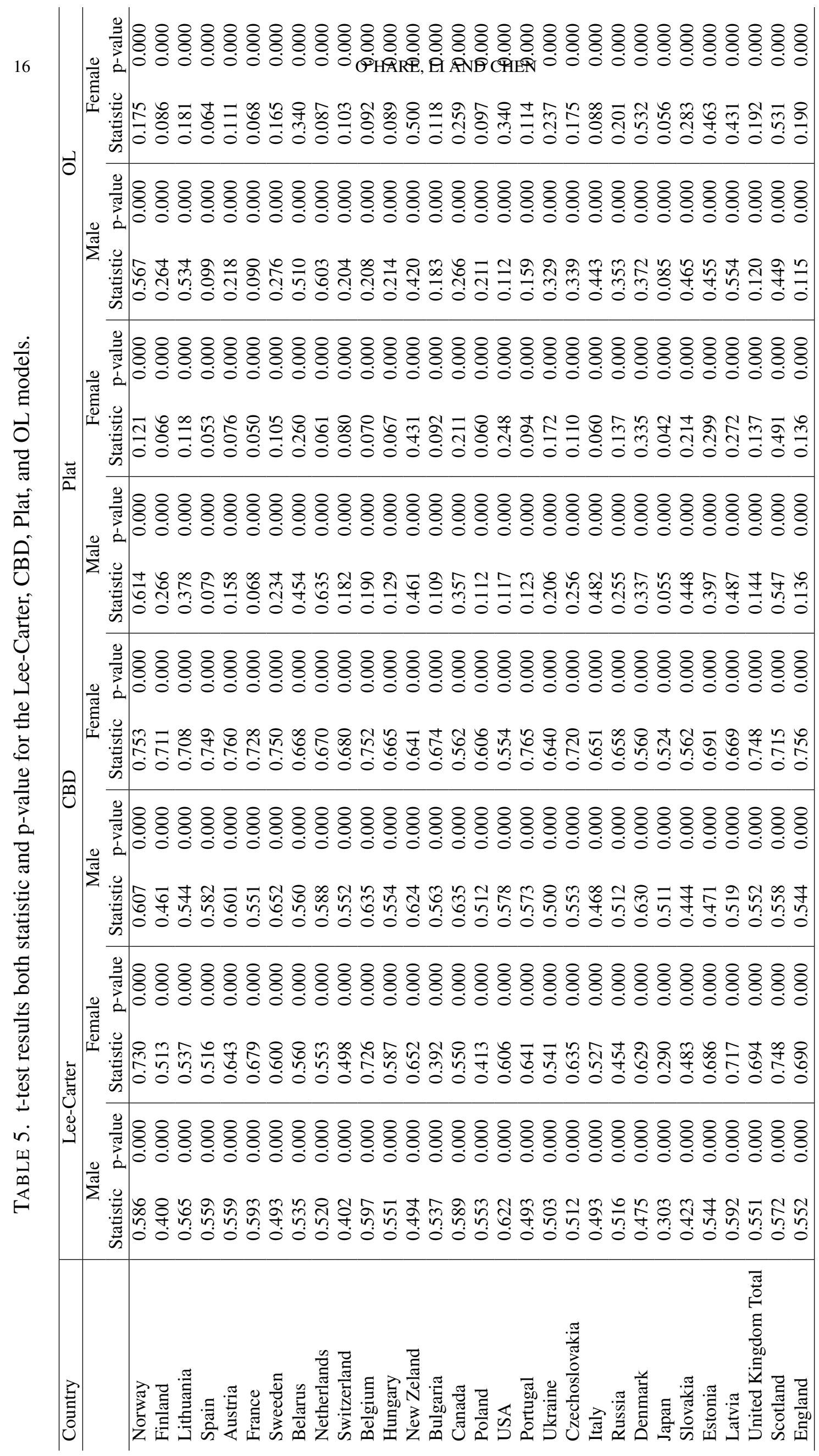


5.3.2. variance ratio tests. 
‡ ৪ ৪ ৪ ৪ ৪ ৪ ৪ ৪ ৪ ৪ ৪ ৪ ৪ ৪ ৪ ৪ ৪ ৪ ৪ ৪ ৪

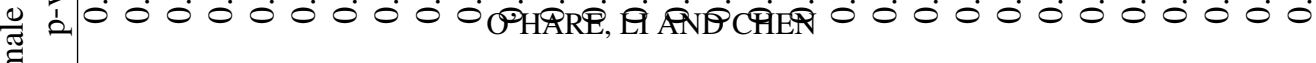

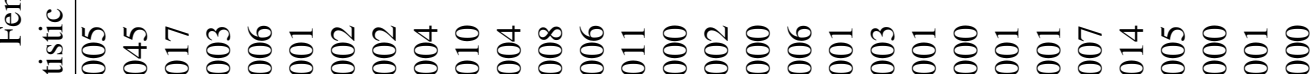
$\dot{\omega}$

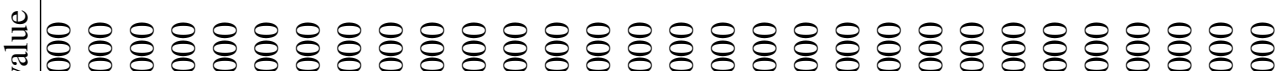
$\frac{\sqrt{3}}{3}$

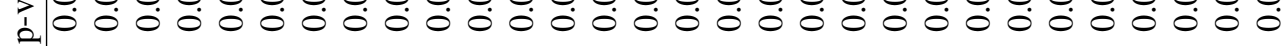
$\sum^{\pi}$

శె

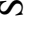

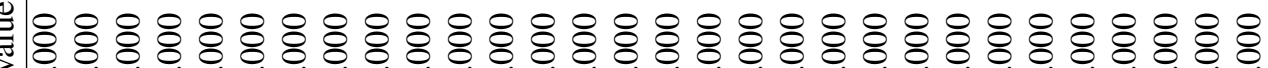

热

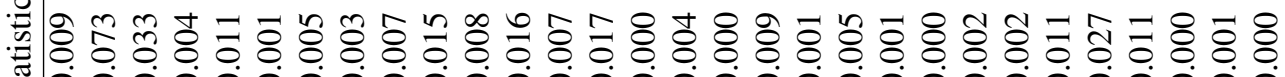

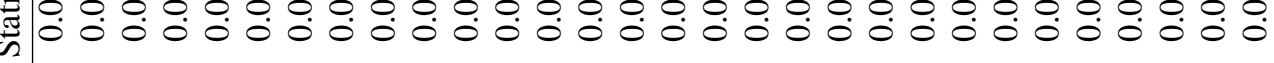

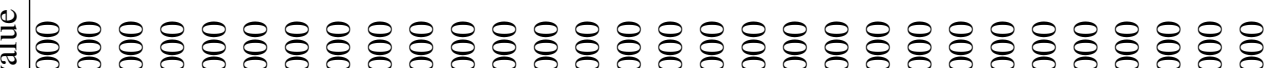

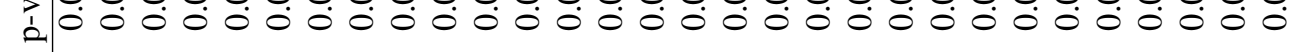

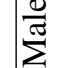

Бํี่

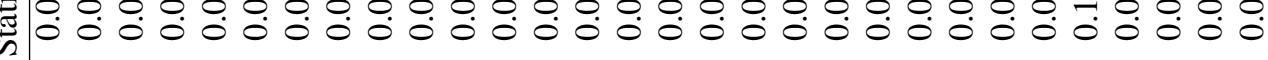

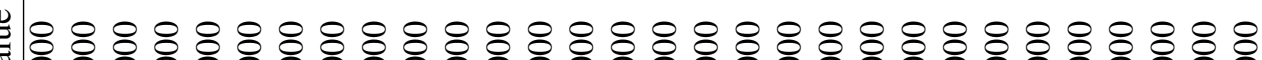

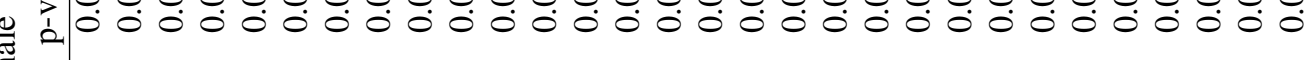
贾

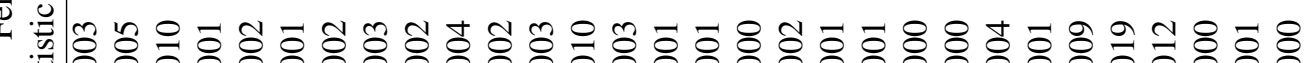

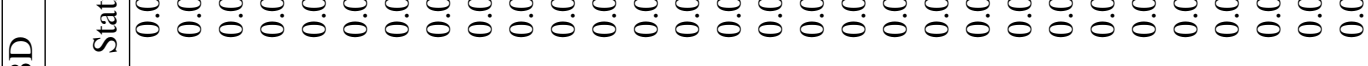

ขิ

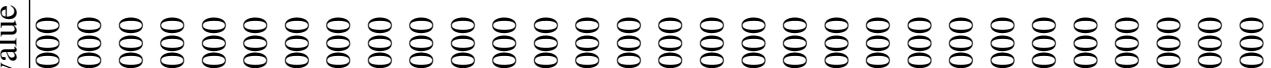
-

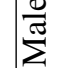

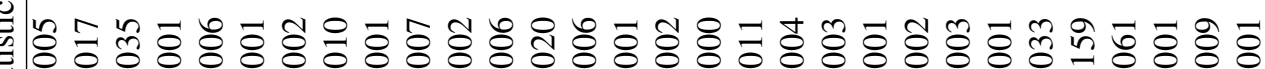

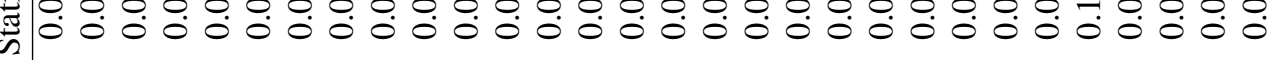

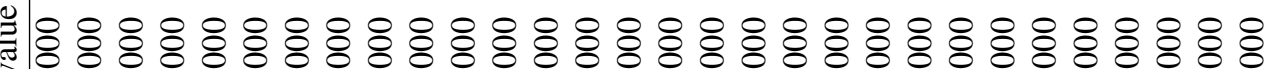
元

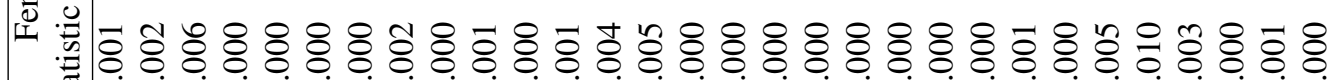

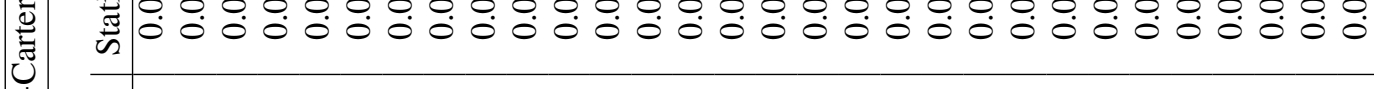

Џ $\frac{0}{\pi}$

1000000000000000000000000000000 $\Sigma$

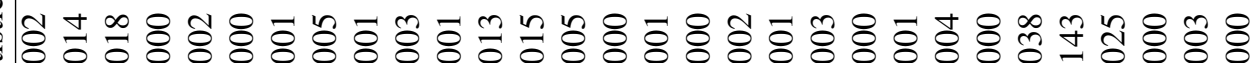

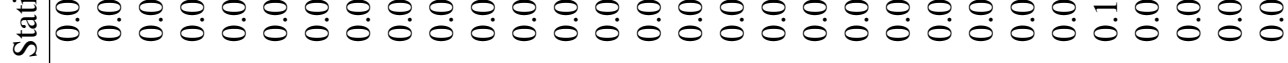

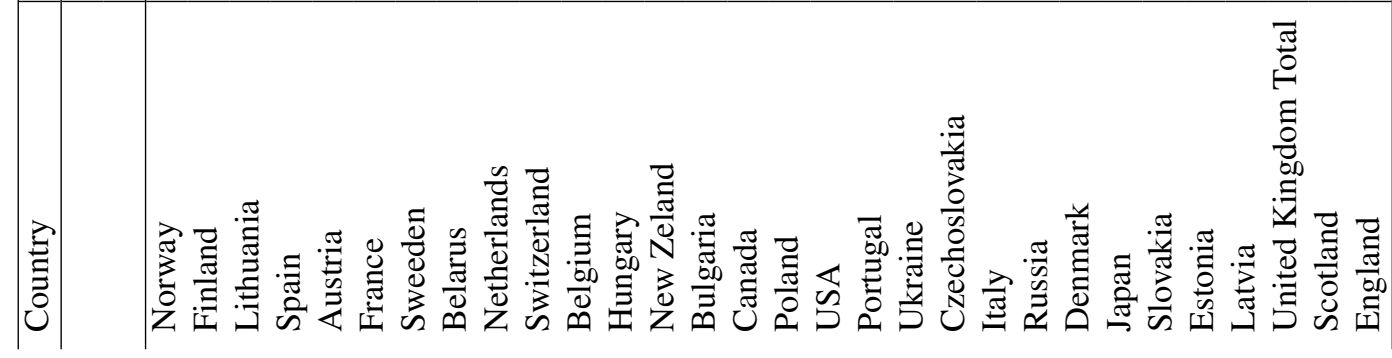


5.3.3. Jaque Bara tests. 


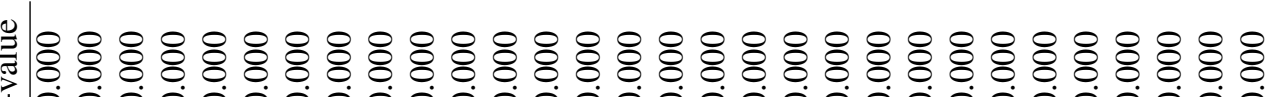
ㄴ.

u .

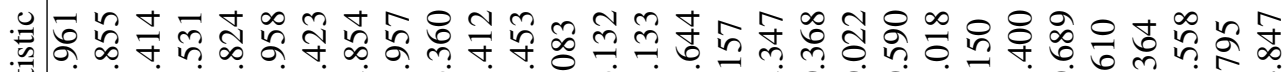

$\overline{0}$

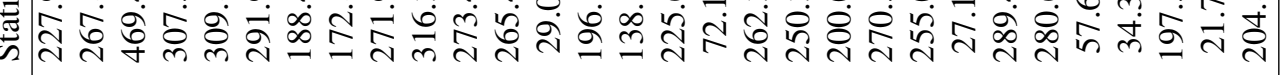

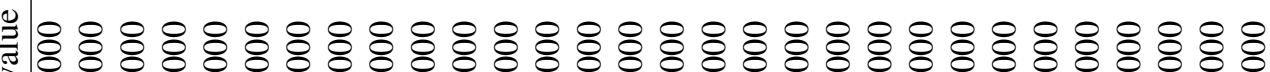

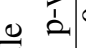

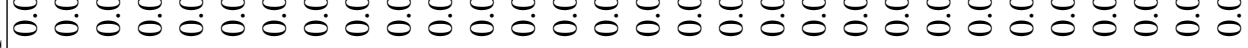

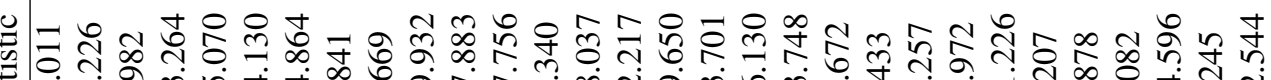
它

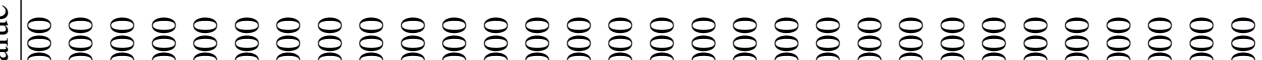
击

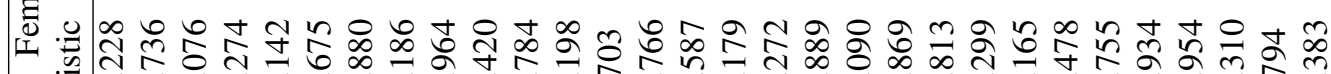
क्र

$\frac{\pi}{2}$

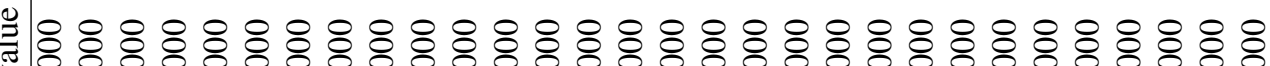

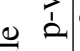

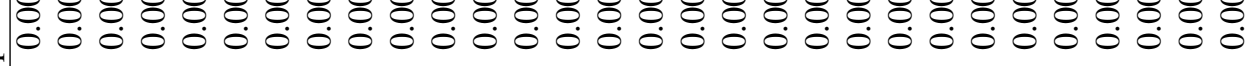

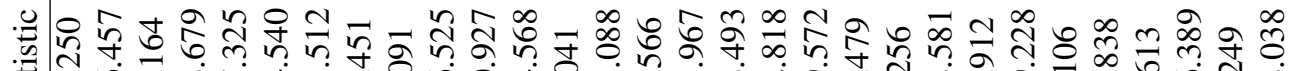

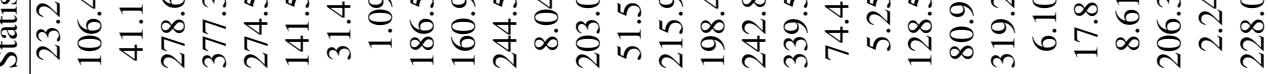

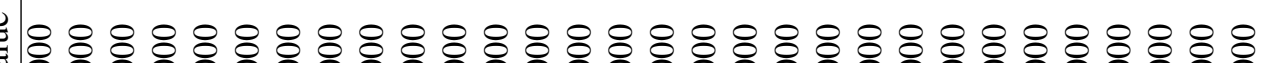

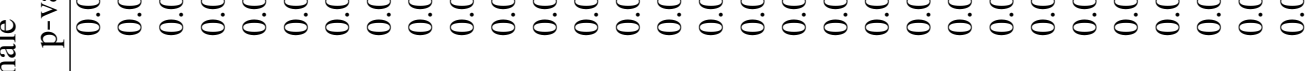
ह

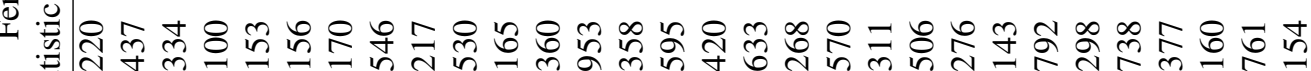
己ิ)

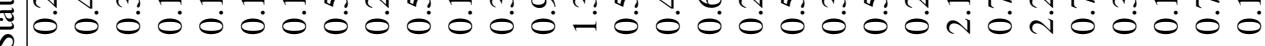

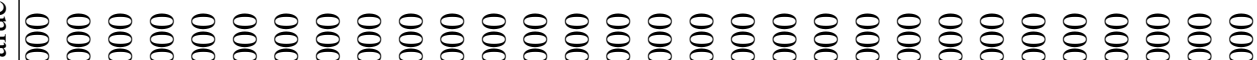

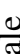

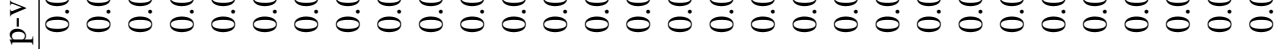

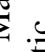

下合

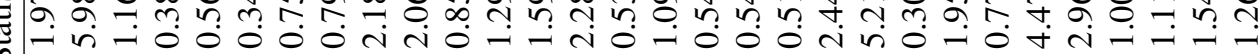

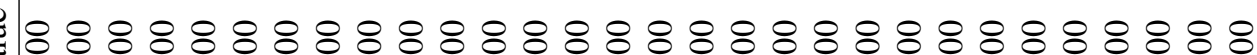

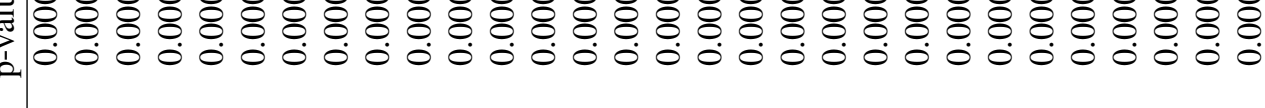

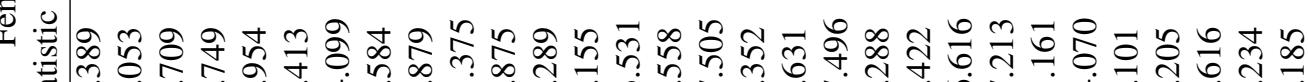
矛

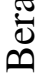

$\underset{\Xi}{\stackrel{\Xi}{*}}$

岁 $\frac{0}{\tilde{\pi}}$

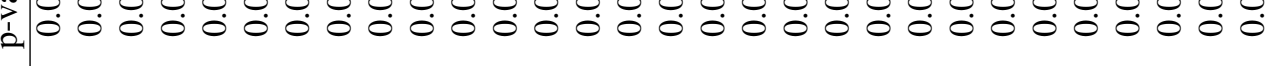
$\sum$.

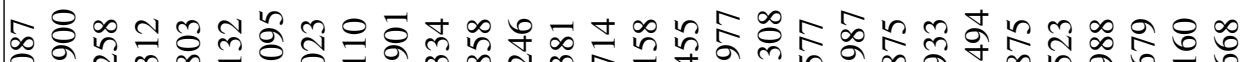

空 $\vec{n}$ ते

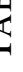

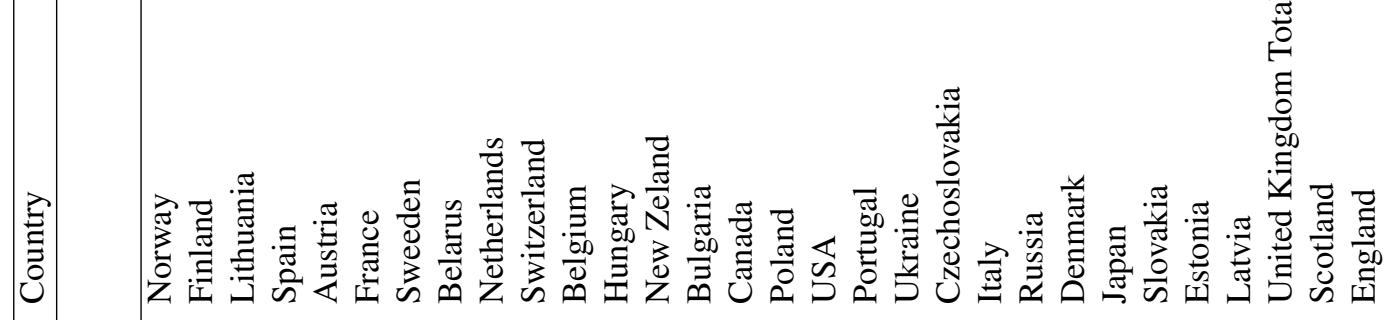


5.3.4. Hurst exponent tests. The hurst exponent calculations are done by first splitting the matrix of residuals into time series of age specific residuals and period specific residuals. In other words by considering the columns and rows of the matrix separately. Of course we might also consider the cohort pattern (or the diagonals) of the matrix also but we defer this to further study. The results presented below should the hurst exponents over period and over age. 
As can be seen for the test results in every case the fitted models fail the basic normality tests suggesting that the residuals mean and variances do not conform to those of the standard normal distribution, nor do the higher moments. In addition, the hurst exponent calculations show long term positive correlation in the residuals both in the age dimension and the period dimension. This suggests that perhaps there is still some structure in the residuals that might be identified. In particular the inclusion of additional period effects (as in the Plat (2009) and Ohare and $\mathrm{Li}(2013)$ models does not compensate for this. This is an area of further research.

\section{Conclusions}

In this paper we have considered several of the leading extrapolative models of mortality rates and have applied normality tests and hurst calculations to the fitted residuals. More specifically we have fitted the models of Lee and Carter (1992), Cairns, Blake and Dowd (2006), Plat (2009) and O'Hare and $\mathrm{Li}$ (2012) to the data for 30 countries for both males and females and tests the resulting residuals using t-tests, variance ratio tests and Jaque bear tests. We have also calculated age and prior hurst exponents for each of the countries and genders and note that exclusively these hurst exponents lie in the region $0.5<1$. This suggests some positive correlations between residuals.

Further research will now focus further on the hurst exponents analysing in more detail the patterns found within these exponents to try to identify what if any structure still remains in the data after fitting such time series model. 


\section{REFERENCES}

[1] Andrews D.W.K. (1993), Tests for parameter instability and structural change with unknown change point, Econometrica, 61, 821-856.

[2] Andrews D.W.K., Ploberger W. (1994), Optimal tests when a nuisance parameter is present only under the alternative, Econometrica, 62, 1383-1414.

[3] Auster, R., Leveson, I. \& Sarachek, D. (1969), The Production of Health, an Exploratory Study, The Journal of Human Resources vol. 4, no. 4, pp. pp. 411-436.

[4] Bai, J. \& Ng, S. (2006), Evaluating latent and observed factors in macroeconomics and finance, Journal of Econometrics vol. 131, no. 1-2, pp. 507-537.

[5] Bai, J. \& Ng, S. (2002), Determining the Number of Factors in Approximate Factor Models, Econometrica vol. 70, no. 1, pp. 191-221.

[6] Bai, J. \& Ng, S. (2007), Determining the Number of Primitive Shocks in Factor Models, Journal of Business and Economic Statistics vol. 25, no. 1, pp. 52-60.

[7] Bai, J. (1994), Least Squares Estimation of a Shift in Linear Processes, Journal of Time Series Analysis, 15, 453-472.

[8] Bai, J. (1997a), Estimating Multiple Breaks One at a Time, Econometric Theory, 13, 315-352.

[9] Bai, J. (1997b), Estimation of a Change Point in Multiple Regression Models, Review of Economics and Statistics, 79, 551-563.

[10] Bai, J., Perron, P., (1998), Estimating and Testing Linear Models With Multiple Structural Changes, Econometrica, 66, 47-78.

[11] Bai, J., Perron, P., (2003), Computation and Analysis of Multiple Structural Change Models, Journal of Applied Econometrics, 18, 1-22.

[12] Banerjee, S., and Carlin, B. P. (2002) Spatial Semiparametric Proportional Hazards Models for Analyzing Infant Mortality Rates in Minnesota Counties, Case Studies in Bayesian Statistics, Volume VI, New York: Springer.

[13] Banerjee, S., and Carlin, B. P. (2003) Semiparametric Spatio-Temporal Frailty Modeling, Environmetrics, 14, 523-535.

[14] Banerjee, S., Wall, M. M., and Carlin, B. P. (2003) Frailty Modeling for Spatially Correlated Survival Data, with Application to Infant Mortality in Minnesota. Biostatistics, 4, 123-142.

[15] Barker, D.J. (1992), Fetal and infant origins of adult disease British Medical Journal.

[16] Barhoumi, K., Darn, O. and Ferrara, L. (2010), Are disaggregate data useful for factor analysis in forecasting French GDP?. Journal of Forecasting, 29, 132144

[17] Barrieu,P., Bensusan,H., El karoui, N., Hillairet, C., Loisel, S., Ravanelli, C., and Salhi, Y., (2010) Understanding, modelling and managing longevity risk: key issues and main challenges, Scandinavian Actuarial Journal, Forthcoming 
[18] Bernardinelli, L., and Montomoli, C. (1992) Empirical Bayes versus Fully Bayesian Analysis of Geographical Variation in Disease Risk. Statistics in Medicine, 11, 983-1007.

[19] Besag, J., York, J. C., and Mollie, A. (1991) Bayesian Image Restoration, with two Applications in Spatial Statistics. Annals of the Institute of Statistical Mathematics, 43, 1-20.

[20] Blake, D. and Burrow, W. (2001), Survivor Bonds: Helping to Hedge Mortality Risk, Journal of Risk and Insurance, vol. 68, no. 2, pp. 339-348.

[21] Blake, D., Courbage, C., MacMinn, R., and Sherris, M., (2011), Longevity Risk and Capital Markets: The 2010-2011 Update, The Geneva Papers no. 36, pp 489-500.

[22] Bell, W. (1997), Comparing and assessing time series methods for forecasting age-specific fertility and mortality rates, Journal of Official Statistics, vol. 13, pp. 279-303.

[23] Bernanke, B.S., Boivin, J. \& Eliasz, P. (2005), Measuring the Effects of Monetary Policy: A FactorAugmented Vector Autoregressive (FAVAR) Approach, The Quarterly Journal of Economics, vol. 120, no. 1, pp. 387-422.

[24] Bethune, A. (1997), Unemployment and mortality, Health inequalities, eds. F. Drever \& M. Whitehead, HMSO, London.

[25] Breeden, D.T., Gibbons, M.R. \& Litzenberger, R.H. (1989), Empirical Test of the Consumption-Oriented CAPM, The Journal of Finance, vol. 44, no. 2, pp. 231-262.

[26] Breitung, J. \& Eickmeier, S. (2006), Dynamic factor models, Allgemeines Statistisches Archiv vol. 90, no. 1, pp. 27-42.

[27] Booth, H., Maindonald, J., Smith, L., (2002). Applying Lee-Carter under conditions of variable mortality decline.Population Studies 56, 325-336.

[28] Booth, H., \& Tickle, L., (2008), Mortality modeling and forecasting: A review of methods, Annals of actuarial science. 3, 3-43.

[29] Brouhns, N., Denuit, M., and Vermunt, J.K., (2002). A Poisson log-bilinear approach to the construction of projected lifetables. Insurance: Mathematics and Economics 31(3), 373-393.

[30] Brown R.L., Durbin J., Evans J.M. (1975), Techniques for testing constancy of regression relationships over time, Journal of the Royal Statistical Society, Series B, 37, 149-163.

[31] Cairns, A.J.G., (2000), A discussion of parameter and model uncertainty in insurance. Insurance: Mathematics and Economics 27(3), 313-330.

[32] Cairns, A.J.G., Blake, D., and Dowd, K., (2006), A two-factor model for stochastic mortality with parameter uncertainty: Theory and calibration. Journal of Risk and Insurance 73, 687-718.

[33] Cairns, A.J.G., Blake, D., Dowd, K., Coughlan, G.D., Epstein, D., Ong, A., and Balevich, I., (2009), A quantitative comparison of stochastic mortality models using data from England \& Wales and the United States. North American Actuarial Journal 13(1), 1-35. 
[34] Cairns, A.J.G., Blake, D., Dowd, K., Coughlan, G.D., Epstein, D., and Khalaf-Allah, M., (2011) Mortality density forecasts: An analysis of six stochastic mortality models.Insurance: Mathematics and Economics 48, 355-367.

[35] Carter, L. R., \& Prskawetz., A. (2001) Examining Structural Shifts in Mortality Using the Lee-Carter Method. Working Paper WP 2001-007, Max Planck Institute for Demographic Research

[36] Chamberlain, G. and Rothschild, M. (1983), Arbitrage, Factor Structure, and Mean-Variance Analysis on Large Asset Markets, Econometrica, vol. 51, no. 5, pp. 1281-1304.

[37] Chu, C.S., Hornik, K., Kuan, C.M. (1995), MOSUM tests for parameter constancy, Biometrika, 82, 603-617.

[38] Clayton, D. \& Schifflers, E., (1987). Models for temporal variation in cancer rates. II: Age-period-cohort models. Statistics in Medicine, 6, 469-481.

[39] CMI, (1990). Continuous Mortality Investigation Reports, 1990. Institute of Actuaries and Faculty of Actuaries.

[40] CMI, (1999). Continuous Mortality Investigation Reports, 1999. Institute of Actuaries and Faculty of Actuaries.

[41] CMI, (2002). Continuous Mortality Investigation Reports,2002. Institute of Actuaries and Faculty of Actuaries.

[42] CMI, (2005). Continuous Mortality Investigation Reports,2005. Institute of Actuaries and Faculty of Actuaries.

[43] CMI, (2006). Stochastic projection methodologies: Further progress and P-Spline model features, example results and implications. Working Paper 20.

[44] CMI, (2007). Stochastic projection methodologies: Lee- Carter model features,example results and implications. Working Paper 25.

[45] Connor, G.,Hagmann, M. \& Linton, O. (2011), Efficient Semiparametric Estimation of the Fama-French Model and Extensions, forthcoming in Econometrica.

[46] Cochrane, J. H. (1988) How big is the random walk in GNP? Journal of Political Economy, 96, 893-920.

[47] Coelho, E. and Nunes, L. C. (2011), Forecasting mortality in the event of a structural change. Journal of the Royal Statistical Society: Series A (Statistics in Society), 174, 713-736.

[48] Coughlan, G.D., Epstein, D., Ong, A., Sinha, A., Balevich, I., Hevia Portocarrera, J., Gingrich, E.,KhalafAllah, M., and Joseph, P., (2007), LifeMetrics: A toolkit for measuring and managing longevity and mortality risks. Technical Document (JPMorgan, London, 13 March). Available at www.lifemetrics.com.

[49] Cressie, N. A. (1993) Statistics for Spatial Data. New York: Wiley.

[50] Currie, I.D., Durban, M., and Eilers, P.H.C., (2004). Smoothing and forecasting mortality rates. Statistical Modelling 4, 279-298.

[51] Currie, I.D., (2006) Smoothing and forecasting mortality rates with P-splines.Presentation to the Institute of Actuaries. Available at: http://www.ma.hw.ac.uk/iain/research.talks.html.

[52] Currie, I.D., (2011) Modelling and forecasting the mortality of the very old. ASTIN Bulletin, 41, 419-427. 
[53] Cutler, D.,M., Glaeser, E.L. \& Rosen, A.B. (2009), Is the U.S. Population Behaving Healthier? Social Security Policy in a Changing Environment, eds. J.R. Brown, J.B. Liebman \& D.A. Wise, National Bureau of Economic Research, University of Chicago Press pp. 423-442.

[54] Cutler, D.,M. \& Meara, E. (2000), The Technology of Birth: Is It Worth It?, Forum for Health Economics \& Policy. Vol. 3, no. (Frontiers in Health Policy Research), Article 3.

[55] Cutler, D.M. \& Meara, E. (2004), Changes in the Age Distribution of Mortality over the Twentieth Century. Perspectives on the Economics of Aging University of Chicago Press, , pp. 333-366.

[56] Cutler, D., Deaton, A. \& Lleras-Muney, A. (2006), The Determinants of Mortality, The Journal of Economic Perspectives vol. 20, no. 3, pp. 97-120.

[57] D’Agostino, Antonello \& Giannone, Domenico, (2007), Comparing Alternative Predictors Based on LargePanel Factor Models, CEPR Discussion Papers 6564, C.E.P.R. Discussion Papers.

[58] Delwarde, A., Denuit, M., and Eilers, P., (2007), Smoothing the Lee \& Carter and Poisson log-bilinear models for mortality forecasting: A penalized log-likelihood approach. Statistical Modelling, 7, 29-48.

[59] De Jong, P., and Tickle, L., (2006), Extending the Lee \& Carter model of mortality projection. Mathematical Population Studies, 13, 1-18.

[60] Dickson, D.C., Hardy, M.R., Waters, H.R., (2009), Actuarial Mathematics for Life Contingent Risks, Cambridge University Press.

[61] Doksum, K. A., and Gasko, M. (1990) On a Correspondence Between Models in Binary Regression Analysis and in Survival Analysis. International Statistical Review, 58, 243-252.

[62] Doornik, J. A. and Hansen, H. (1994) An omnibus test for univariate and multivariate normality. Working Paper, Nuffield College, Oxford

[63] Dowd, K., Blake, D., Cairns, A.J.G., Dawson, P., (2006), Survivor Swaps, Journal of Risk and Insurance, vol. 73 , no. 1 , pp. 117 .

[64] Dowd, K., Cairns, A.J.G., Blake, D., Coughlan, G.D., Epstein, D., and Khalaf-Allah, M. (2008), Backtesting stochastic mortality models: An ex-post evaluation of multi-period-ahead density forecasts. Pensions Institute Discussion Paper PI-0803,March.

[65] Dowd, K., Cairns, A.J.G., Blake, D., Coughlan, G.D., Epstein, D., and Khalaf-Allah, M., (2010), Backtesting stochastic mortality models: An ex-post evaluation of multi-period-ahead density forecasts, North American Actuarial Journal (14)3, 281-298.

[66] Dowd, K., Cairns, A.J.G., Blake, D., Coughlan, G.D., Epstein, D., and Khalaf-Allah, M., (2010a). Evaluating the Goodness of fit of stochastic mortality models Insurance Mathematics and Economics 47, 255-265.

[67] Eberly, L. E., and Carlin, B. P. (2000) Identifiability and Convergence Issues for Markov Chain Monte Carlo Fitting of Spatial Models. Statistics in Medicine, 19, 2279-2294.

[68] Ecker, M. D., and Gelfand, A. E. (1999) Bayesian Modeling and Inference for Geometrically Anisotropic Spatial Data. Mathematical Geology, 31, 67-83. 
[69] Fupuy-Wong, C., Haberman, S., (2004), Projecting Mortality Trends: Recent Developments in the UK and the US, North American Actuarial Journal, 8(2), p.56-83

[70] Freeman, D.G. (2003), Is health care a necessity or a luxury? Pooled estimates of income elasticity from US state-level data, Applied Economics vol. 35, no. 5, pp. 495-502.

[71] Forni, M., Hallin, M., Lippi, M. and Reichlin, L. (2005), The Generalized Dynamic Factor Model, Journal of the American Statistical Association, vol. 100, no. 471, pp. 830-840.

[72] Geweke, J. (1977), The Dynamic Factor Analysis of Economic Time Series, in Latent Variables in SocioEconomic Models, eds. D. J. Aigner and A. S. Goldberger, Amsterdam: North-Holland, pp. 365-383.

[73] Girosi, F. and G. King (2008), Demographic Forecasting, Princeton: Princeton University Press .

[74] Girosi, F., and King, G., (2005). A reassessment of the Lee-Carter mortality forecasting method, Working Paper, Harvard University.

[75] Government Actuary’s Department (1995). National population projections 1992-based. H.M.S.O., London.

[76] Government Actuary's Department (2001). National population projections: review of methodology for projecting mortality. London.

[77] Government Actuary's Department (2002). National population projections 2000-based. H.M.S.O., London.

[78] Grubesic, T. H. (2004) The Geodemographic Correlates of Broadband Access and Availability in the United States. Telematics and Informatics, 21, 335-358.

[79] Hendry, D. F. and H.-M. Krolzig (2001). Automatic Econometric Model Selection using PcGets. London: Timberlake Consultants Pres

[80] Hendry, D. F. (2000) Epilogue: the success of general-to-specific model selection, in D.F. Hendry, Econometrics: Alchemy or Science? (New Edition). Oxford. Oxford University Press

[81] Hári, N., Waegenaere, A., Melenberg, B. and Nijman, T., (2008). Estimating the term structure of mortality. Insurance: Mathematics and Economics 42, 492-504.

[82] Haberman S, and Renshaw A.E., (1996), Generalized Linear Models and Actuarial Science, The Statistician, vol. 45, pp.407-436

[83] Hamilton, J.D., (1994), Times Series Analysis, Cambridge University Press.

[84] Harris, D., Harvey, D. I., Leybourne, S. J. and Taylor, A. M. R. (2009) Testing for a unit-root in the presence of a possible break in trend. Econmetric Theory, 25, 1545-1588.

[85] Harvey, D. I., Leybourne, S. J. and Taylor, A. M. R. (2009) Simple, robust and powerful tests of the changing trend hypothesis. Econmetric Theory, 25, 995-1029.

[86] Hauser, R.M., and Weir,D.R., (2011). Recent Developments in Longitudinal Studies of Aging. Demography.

[87] Heligman. L., \& Pollard, J. H. (1980). The age pattern of mortality. Journal of the Institute of Actuaries, 107(1, No 434), 49-80.

[88] Hendry, D.F. and Neale, A. J. (1991) A Monte Carlo study of the effects of structural changes on tests for unit-roots. Economic Structural Change, Analysis, and Forecasting (eds P. Hackl and A. H. Westlund), pp. 95119. New York: Springer. 
[89] Hendry, D.F. (2000) Epilogue: the success of general-to-specific model selection, in D.F. Hendry, Econometrics: Alchemy or Science? (New Edition). Oxford: Oxford University Press.

[90] Herskind, A., McGue, M., Holm, N., Srensen, T., Harvald, B. \& Vaupel, J. (1996), The heritability of human longevity: A population-based study of 2872 Danish twin pairs born 1870-1900, Human genetics, vol. 97, no. 3 , pp. 319-323.

[91] Human Mortality Database (HMD), (2004). University of California, Berkeley (USA), and Max Planck Institute for Demographic Research, Rostock (Germany). http://www.mortality.org or http://www.humanmortality.de.

[92] Hyndman, R.J. \& Ullah, S. (2005), Robust forecasting of mortality and fertility rates: A functional data approach (working paper), Department of Economics and Business Statistics, Monash University, Melbourne.

[93] Im, K. S., Pesaran, M. H. and Shin, Y. (2003). Testing for unit roots in heterogeneous panels. Journal of Econometrics vol. 115, pp. 5374.

[94] Iversen, L., Andersen, O., Andersen, P.K., Christoffersen, K. \& Keiding, N. (1987), Unemployment and mortality in Denmark, 1970-80, British Medical Journal (Clinical research ed.), vol. 295, no. 6603, pp. $879-884$.

[95] Ingram, D. D., and Kleinman, J. C. (1989) Empirical Comparisons of Proportional Hazards and Logistic Regression Models. Statistics in Medicine, 8, 525-538.

[96] Jolliffe, I. T. (1986), Principal component analysis, New York: Springer, University of Geneva.

[97] Kannisto, V., Lauristen, J., Thatcher, A.R., \& Vaupel. J.W., (1994) Reduction in Mortality at Advanced Ages: Several Decades of Evidence from 27 Countries. Population Development Review, 20, 793-810.

[98] Kazembe, L. N. (2007) Spatial Modelling and Risk Factors of Malaria Incidence in Northern Malawi. Acta Tropica, 102, 126-137.

[99] King, G., and Soneji, S., (2011) The Future of Death in America. Demographic Research 25, 1-38.

[100] Koissi, M.C., Shapiro, A.F., \& Hognas, G. (2005) Evaluating and Extending the Lee-Carter Model for Mortality Forecasting: Bootstrap Confidence Interval. Insurance: Mathematics and Economics, 38, 1-20.

[101] Krolzig, H-M. and Hendry, D.F. (2001). Computer Automation of General-to-Specific Model Selection Procedures. Journal of Economic Dynamics and Control, vol. 25, pp. 831-866

[102] Kuan, C.M., \& Hornik, K. (1995), The generalized fluctuation test: A unifying view, Econometric Reviews, $14,135-161$.

[103] Kuntsche, E., Rehm, J. \& Gmel, G. (2004), Characteristics of binge drinkers in Europe, Social science \& medicine, vol. 59, no. 1, pp. 113-127.

[104] Kuulasmaa, K., Tunstall-Pedoe, H., Dobson, A., Fortmann, S., Sans, S., Tolonen, H., Evans, A. \& Ferrario, M. (2000), Estimation of contribution of changes in classic risk factors to trends in coronary-event rates across the WHO MONICA Project populations, The Lancet vol. 355, no. 9205, pp. 675-687.

[105] Lee, R.D. \& Carter, L.R. (1992), Modeling and Forecasting U. S. Mortality, Journal of the American Statistical Association, 87(419), 659-671. 
[106] Lee, R. D., and Miller, T., (2001) Evaluating the performance of the Lee-Carter method for forecasting mortality, Demography, 38, 537-549.

[107] Leon, D.A. (2011), Trends in European life expectancy: a salutary view. International Journal of Epidemiology, vol. 40, no.2, pp. 271-277.

[108] Li, J.S.H., Chan, W.S. \& Cheung, S.H. (2011) Structural Changes in the Lee-Carter Mortality Indexes: Detection and Implications, North American Actuarial Journal, 15, 13-31.

[109] Lo, A. W., and A. C. MacKinley (1988) Stock prices do not follow random walks: Evidence based on a simple specification test. Review of Financial Studies 1: 41-66.

[110] Lo, A. W., and A. C. MacKinley (1989) The size and power of the variance ratio test in finite samples: A monte carlo investigation. Journal of Econometrics 40: 203-38.

[111] Murphy, Michael J. (2010) Reexamining the dominance of birth cohort effects on mortality. Population and development review, vol. 36, no.2. pp. 365-390.

[112] McGilchrist, C. A., and Aisbett, C. W. (1991) Regression with Frailty in Survival Analysis. Biometrics, 47, 461-466.

[113] Miller, R.D.J. \& Frech, H.E.I. (2000), Is There a Link Between Pharmaceutical Consumption and Improved Health in OECD Countries?, PharmacoEconomics, vol. 18, no. 3, pp. 33-45.

[114] Moscone, F. \& Tosetti, E. (2010), Health expenditure and income in the United States, Health Economics, vol. 19 , pp. 1385-1403.

[115] NIRSA (2010) Northern Ireland Multiple Deprivation Study. http://www.nisra.gov.uk/ deprivation/archive/Updateof2005Measures/NIMDM_2010_Report.pdf

[116] Ngianga-Bakwin, K., and Madise, N. (2004) The Spatial Epidemiology of Childhood Diseases in Malawi and Zambia. African Population Stuides, 19, 191-218.

[117] O'Hare, C., and Li, Y. (2012), Explaining young mortality, Insurance: Mathematics and Economics, 50(1), $12-25$

[118] Organization for Economic Cooperation and Development (2009), OECD Health Data 2009: Statistics and Indicators for 30 Countries, Paris.

[119] Ostro, B.D. (1983), The effects of air pollution on work loss and morbidity, Journal of Environmental Economics and Management, vol. 10, no. 4, pp. 371-382.

[120] Plat, R., (2009), On stochastic mortality Modeling. Insurance: Mathematics and Economics, 45(3), 393404.

[121] Ploberger, W., Krämer, W. (1992), The CUSUM test with OLS residuals, Econometrica, 60, 271-285.

[122] Renshaw, A.E., Haberman, S., (2003), Lee-Carter mortality forecasting with age-specific enhancement.Insurance: Mathematics and Economics, 33, 255-272.

[123] Renshaw, A.E., Haberman, S., (2006) A cohort-based extension to the Lee-Carter model for mortality reduction factors. Insurance: Mathematics and Economics, 38, 556-70. 
[124] Richards, S., and Jones, G. (2004) Financial Aspects of Longevity Risk. Staple Inn Actuarial Society, London.

[125] Richards, S. J. (2008) Applying Survival Models to Pensioner Mortality Data. Institute of Actuaries Sessional Meeting Paper.

[126] Rosen, S. (1974) Hedonic Prices and Implicit Markets: Product Differentiation in Pure Competition. The Journal of Political Economy, 82, 34-55.

[127] Ruhm, C.J. (2004), Macroeconomic Conditions, Health and Mortality, National Bureau of Economic Research.

[128] Sargent, T.J. and Sims, C. (1977), Business Cycle Modeling Without Pretending to Have Too Much a Priori Theory New methods of Business Cycle Research, ed. C. Sims, Federal Reserve Bank of Minneapolis, Minneapolis.

[129] Schwartz, J. \& Dockery, D.W. (1992), Increased mortality in Philadelphia associated with daily air pollution concentrations, American Review of Respiratory Disease vol. 145, pp. 600-604.

[130] Shang, H. L., Booth, H., Hyndman, R. J. (2011). Point and interval forecasts of mortality rates and life expectancy: A comparison of ten principal component methods. Demographic Research, 25, 173-214.

[131] Sherris, M., and Tang. A.,(2010). http://papers.ssrn.com/sol3/papers.cfm?abstract_ id $=1594522$

[132] Spiegelhalter, D. J., Best, N. G., Carlin, B. P., and van der Linde, A. (2002) Bayesian Measures of Model Complexity and Fit. Journal of the Royal Statistical Society, 64, 583-639.

[133] Stein, M. L. (1999) Interpolation of Spatial Data: Some Theory for Kriging. New York: Springer.

[134] Stewart, S.T., Cutler, D.M. \& Rosen, A.B. (2009), Forecasting the Effects of Obesity and Smoking on U.S. Life Expectancy, New England Journal of Medicine, vol. 361, no. 23, pp. 2252-2260.

[135] Stock, J.H. \& Watson, M.W. (2002), Macroeconomic Forecasting Using Diffusion Indexes, Journal of Business \& Economic Statistics vol. 20, no. 2, pp. pp. 147-162.

[136] Thornton, J., (2002), Estimating a health production function for the US: some new evidence, Applied Economics vol. 34, no. 1, pp. 59-62.

[137] Thornton, P. E., B. Law, H. Gholz, K. Clark, E. Falge, and D. Ellsworth, et al., (2002) Modeling and measuring the effects of disturbance history and climate on carbon and water budgets in evergreen needleleaf forests, Agricultural and Forest Meteorology 113185222

[138] Tulijapurkar, S., (2008), Mortality declines, Longevity risk and Aging. Asia-Pacific Journal of Risk and Insurance vol. 3(1), pp. 37-51.

[139] Tuljapurkar, S., and Boe, C. (1998) Mortality Change and Forecasting: How Much and How Little Do We Know? North American Actuarial Journal, 2, 13-47.

[140] Turrell, G., Kavanagh, A., and Subramanian, S. V. (2006) Area Variation in Mortality in Tasmania (Australia): the Contributions of Socioeconomic Disadvantage, Social Capital and Geographic Remoteness. Health and Place, 12, 291-305. 
[141] Unal, B., Critchley, J.A. \& Capewell, S. (2004) Explaining the Decline in Coronary Heart Disease Mortality in England and Wales Between 1981 and 2000, Circulation vol. 109, no. 9, pp. 1101-1107

[142] Vaupel, J. W., Manton, K. G., and Stallard, E. (1979) The Impact of Heterogeneity in Individual Frailty on the Dynamics of Mortality. Demography, 16, 439-454.

[143] Vaupel, J.W., and Kistowski, K. G. V. (2005) Broken Limits to Life Expectancy Oxford Institute of Ageing, Ageing Horizons, No. 3, pp. 613

[144] Vaupel, J.W., (1997) The Remarkable Improvements in Survival at Older Ages. Philosophical Transactions of the Royal Society of London, B 352, 1799-1804.

[145] Waller, L. A., Carlin, B. P., Xia, H., and Gelfand, A. E. (1997) Hierarchical Spatio-Temporal Mapping of Disease Rates. Journal of the American Statistical Association, 92, 607-617.

[146] Waller, L. A., Zhu, L., Gotway, C. A., Gorman, D. M., and Gruenewald, P. J. (2007) Quantifying Geographic Variations in Associations between Alcohol Distribution and Violence: A Comparison of Geographically Weighted Regression and Spatially Varying Coefficient Models. Stochastic Environmental Research and Risk Assessment, 21, 573-588.

[147] Weir, D.R., (2010) Grand Challenges for the scientific study of aging. Available at http://www.aeaweb.org/econwhitepapers/whitepapers/DavidWeir.pdf

[148] Westerlund, J. (2007), Testing for Error Correction in Panel Data, Oxford Bulletin of Economics \& Statistics, vol. 69 , no. 6 , pp. 709-748.

[149] Wienke, A. (2003) Frailty Models. Working Paper, Max Planck Institute for Demographic Research, Germany.

[150] Wilkinson, D., Hiller, J., Moss, J., Ryan, P., and Worsley, T. (2000) Mortality Variation Across Australia: Descriptive Data for States and Territories, and Statistical Divisions. Australian and New Zealand Journal of Publich Health, 24, 226-233.

[151] Wilkinson, R.G. \& Marmot, M.G. (2003), Social determinants of health: the solid facts, World Health Organization, Regional Office for Europe.

[152] Yang, S.S., Yue, J.C. \& Huang, H. (2010), Modeling longevity risks using a principal component approach: A comparison with existing stochastic mortality models, Insurance: Mathematics and Economics vol. 46, no. 1, pp. 254-270.

[153] Zimmerman, D. (1993) Another Look at Anisotropy in Geostatistics. Mathematical Geology, 25, 453-470.

[154] Zweifel, P., Breyer, F., Kifmann, M. \& Kifmann, M. (2009), Health Economics, Springer.

[155] Zeileis, A., (2000) p-values and alternative boundaries for CUSUM tests. Working Paper 78, SFB Adaptive Information Systems and Modelling in Economics and Management Science, http://www.wu-wien. ac . at/am/wp00.htm\#78.

[156] Zeileis, A., Kleiber C., Kramer W., Hornik K. (2003), Testing and Dating of Structural Changes in Practice, Computational Statistics and Data Analysis, 44, 109-123. 
[157] Zeileis, A., (2005), A Unified Approach to Structural Change Tests Based on ML Scores, F Statistics and OLS Residuals. Econometric Reviews, 24, 445-466.

[158] Zivot, E., \& Andrews, D., (1992), Further Evidence of the Great Crash, the Oil-Price Shock and the UnitRoot Hypothesis. Journal of Business and Economic Statistics, 10, 251-270. 